\title{
Distance Learning in Higher Education During Covid-19
}

\section{OPEN ACCESS}

Edited by:

Nurbiha Shukor,

University of Technology Malaysia,

Malaysia

Reviewed by:

Balwant Singh,

Partap College of Education, India

*Correspondence:

Alfiya R. Masalimova

alfkazan@mail.ru

tORCID:

Alfiya R. Masalimova orcid.org/0000-0003-3711-2527

Maria A. Khvatova

orcid.org/0000-0002-2156-8805

Lyudmila S. Chikileva

orcid.org/0000-0002-4737-9041

Elena P. Zvyagintseva orcid.org/0000-0001-7078-0805

Valentina V. Stepanova

orcid.org/0000-0003-0495-0962

Mariya V. Melnik

orcid.org/0000-0001-8800-4628

Specialty section:

This article was submitted to

Higher Education,

a section of the journal

Frontiers in Education

Received: 26 November 2021

Accepted: 14 February 2022

Published: 03 March 2022

Citation:

Masalimova AR, Khvatova MA,

Chikileva LS, Zvyagintseva EP,

Stepanova W and Melnik MV (2022)

Distance Learning in Higher Education

During Covid-19.

Front. Educ. 7:822958.

doi: 10.3389/feduc.2022.822958

\begin{abstract}
Alfiya R. Masalimova ${ }^{1 * t}$, Maria A. Khvatova ${ }^{2 t}$, Lyudmila S. Chikileva ${ }^{3 t}$, Elena P. Zvyagintseva ${ }^{3+}$, Valentina V. Stepanova ${ }^{4 t}$ and Mariya V. Melnik ${ }^{5 t}$
\end{abstract}

' Department of Pedagogy of Higher Education, Kazan (Volga Region) Federal University, Kazan, Russia, ${ }^{2}$ Department of Jurisprudence, Bauman Moscow State Technical University, Moscow, Russia, ${ }^{3}$ Department of English for Professional Communication, Financial University under the Government of the Russian Federation, Moscow, Russia, ${ }^{4}$ Department of Foreign Languages, RUDN University, Moscow, Russia, ${ }^{5}$ Department of Medical and Social Assessment, Emergency, and Ambulatory Therapy, I.M. Sechenov First Moscow State Medical University (Sechenov University), Moscow, Russia

COVID-19's pandemic has hastened the expansion of online learning across all levels of education. Countries have pushed to expand their use of distant education and make it mandatory in view of the danger of being unable to resume face-to-face education. The most frequently reported disadvantages are technological challenges and the resulting inability to open the system. Prior to the pandemic, interest in distance learning was burgeoning, as it was a unique style of instruction. The mini-review aims to ascertain students' attitudes about distant learning during COVID-19. To accomplish the objective, articles were retrieved from the ERIC database. We utilize the search phrases "Distance learning" AND "University" AND "COVID." We compiled a list of 139 articles. We chose papers with "full text" and "peer reviewed only" sections. Following the exclusion, 58 articles persisted. Then, using content analysis, publications relating to students' perspectives on distance learning were identified. There were 27 articles in the final list. Students' perspectives on distant education are classified into four categories: perception and attitudes, advantages of distance learning, disadvantages of distance learning, and challenges for distance learning. In all studies, due of pandemic constraints, online data gathering methods were selected. Surveys and questionnaires were utilized as data collection tools. When students are asked to compare face-toface and online learning techniques, they assert that online learning has the potential to compensate for any limitations caused by pandemic conditions. Students' perspectives and degrees of satisfaction range widely, from good to negative. Distance learning is advantageous since it allows for learning at any time and from any location. Distance education benefits both accomplishment and learning. Staying at home is safer and less stressful for students during pandemics. Distance education contributes to a variety of physical and psychological health concerns, including fear, anxiety, stress, and attention problems. Many schools lack enough infrastructure as a result of the pandemic's rapid transition to online schooling. Future researchers can study what kind of online education methods could be used to eliminate student concerns.

\footnotetext{
Keywords: ICT, distance learning, COVID-19, higher education, online learning
} 


\section{INTRODUCTION}

The pandemic of COVID-19 has accelerated the spread of online learning at all stages of education, from kindergarten to higher education. Prior to the epidemic, several colleges offered online education. However, as a result of the epidemic, several governments discontinued face-to-face schooling in favor of compulsory distance education.

The COVID-19 problem had a detrimental effect on the world's educational system. As a result, educational institutions around the world developed a new technique for delivering instructional programs (Graham et al., 2020; Akhmadieva et al., 2021; Gaba et al., 2021; Insorio and Macandog, 2022; Tal et al., 2022). Distance education has been the sole choice in the majority of countries throughout this period, and these countries have sought to increase their use of distance education and make it mandatory in light of the risk of not being able to restart face-toface schooling (Falode et al., 2020; Gonçalves et al., 2020; Tugun et al., 2020; Altun et al., 2021; Valeeva and Kalimullin, 2021; Zagkos et al., 2022).

\section{What Is Distance Learning}

Britannica defines distance learning as "form of education in which the main elements include physical separation of teachers and students during instruction and the use of various technologies to facilitate student-teacher and studentstudent communication" (Simonson and Berg, 2016). The subject of distant learning has been studied extensively in the fields of pedagogics and psychology for quite some time (Palatovska et al., 2021).

The primary distinction is that early in the history of distant education, the majority of interactions between professors and students were asynchronous. With the advent of the Internet, synchronous work prospects expanded to include anything from chat rooms to videoconferencing services. Additionally, asynchronous material exchange was substantially relocated to digital settings and communication channels (Virtič et al., 2021).

Distance learning is a fundamentally different way to communication as well as a different learning framework. An instructor may not meet with pupils in live broadcasts at all in distance learning, but merely follow them in a chat if required (Bozkurt and Sharma, 2020). Audio podcasts, films, numerous simulators, and online quizzes are just a few of the technological tools available for distance learning. The major aspect of distance learning, on the other hand, is the detailed tracking of a student's performance, which helps to develop his or her own trajectory. While online learning attempts to replicate classroom learning methods, distant learning employs a computer game format, with new levels available only after the previous ones have been completed (Bakhov et al., 2021).

In recent years, increased attention has been placed on eLearning in educational institutions because to the numerous benefits that have been discovered via study. These advantages include the absence of physical and temporal limits, the ease of accessing material and scheduling flexibility, as well as the cost-effectiveness of the solution. A number of other studies have demonstrated that eLearning is beneficial to both student gains and student performance. However, in order to achieve the optimum results from eLearning, students must be actively participating in the learning process - a notion that is commonly referred to as active learning - throughout the whole process (Aldossary, 2021; Altun et al., 2021).

The most commonly mentioned negatives include technological difficulties and the inability to open the system as a result, low teaching quality, inability to teach applicable disciplines, and a lack of courses, contact, communication, and internet (Altun et al., 2021). Also, misuse of technology, adaptation of successful technology-based training to effective teaching methods, and bad practices in managing the assessment and evaluation process of learning are all downsides of distance learning (Debeş, 2021).

\section{Distance Learning in a Pandemic Context}

The epidemic forced schools, colleges, and institutions throughout the world to close their doors so that students might practice social isolation (Toquero, 2020). Prior to the pandemic, demand for distance learning was nascent, as it was a novel mode of education, the benefits and quality of which were difficult to judge due to a dearth of statistics. But, in 2020, humanity faced a coronavirus pandemic, which accelerated the shift to distant learning to the point that it became the only viable mode of education and communication (Viktoria and Aida, 2020). Due to the advancements in digital technology, educators and lecturers have been obliged to use E-learning platforms (Benadla and Hadji, 2021).

In remote education settings for higher education, activities are often divided into synchronous course sessions and asynchronous activities and tasks. In synchronous courses, learners participate in interactive and targeted experiences that help them develop a fundamental grasp of technology-enhanced education, course design, and successful online instruction. Asynchronous activities and tasks, on the other hand, include tests, group work assignments, group discussion, feedback, and projects. Additionally, asynchronous activities and tasks are carried out via interactive video-based activities, facilitator meetings, live webinars, and keynote speakers (Debeş, 2021).

According to Lamanauskas and Makarskaitè-Petkevičienè (2021), ICT should be attractive for learners. Additionally, student satisfaction with ODL has a statistically significant effect on their future choices for online learning (Virtič et al., 2021). According to Avsheniuk et al. (2021), the majority of research is undertaken to categorize students' views and attitudes about online learning, and studies examining students' perspectives of online learning during the COVID-19 epidemic are uncommon and few. There is presently a dearth of research on the impact on students when schools are forced to close abruptly and indefinitely and transition to online learning communities (Unger and Meiran, 2020). So that, the mini-review is aimed to examining the students' views on using distance learning during COVID-19. 
TABLE 1 | Countries and data collection tools.

\begin{tabular}{|c|c|c|}
\hline Author(s) & Countries & Data collection tools \\
\hline Abrosimova, 2020 & Russia & Questionnaire \\
\hline Adnan and Anwar, 2020 & Pakistan & Survey \\
\hline Akcil and Bastas, 2021 & Cyprus & Attitudes Scale \\
\hline Aldossary, 2021 & Saudi Arabia & Questionnaire \\
\hline Altun et al., 2021 & Turkey & Evaluation form \\
\hline Avsheniuk et al., 2021 & Ukraine & Questionnaire \\
\hline Bakhov et al., 2021 & Ukraine & Survey \\
\hline Beltekin and Kuyulu, 2020 & Turkey & Survey \\
\hline Benadla and Hadji, 2021 & Algeria & Questionnaire \\
\hline Bozavlı, 2021 & Turkey & Questionnaire \\
\hline Didenko et al., 2021 & Ukraine & Questionnaire \\
\hline Glebov et al., 2021 & Russia & Survey \\
\hline Gonçalves et al., 2020 & Portugal & Survey \\
\hline $\begin{array}{l}\text { Kaisar and Chowdhury, } \\
2020\end{array}$ & Bangladesh & Survey \\
\hline $\begin{array}{l}\text { Lamanauskas and } \\
\text { Makarskaitè-Petkevičienè, } \\
2021\end{array}$ & Lithuania & Open questions \\
\hline Lassoued et al., 2020 & $\begin{array}{l}\text { Algerian, Egyptian, } \\
\text { Palestinian, Iraqi }\end{array}$ & Questionnaire \\
\hline Lin and Gao, 2020 & China & Survey \\
\hline Martha et al., 2021 & Indonesia & Questionnaire \\
\hline Mathew and Chung, 2020 & Malaysia & Questionnaire \\
\hline Nenakhova, 2021 & Russia & Questionnaire, interview \\
\hline $\begin{array}{l}\text { Önöral and } \\
\text { Kurtulmus-Yilmaz, } 2020\end{array}$ & Cyprus & Yes-No questions \\
\hline Şahin, 2021 & Turkey & Interview \\
\hline Taşkaya, 2021 & Turkey & Questionnaire \\
\hline Todri et al., 2021 & $\begin{array}{l}\text { Albanians, Italians, } \\
\text { Moroccans, } \\
\text { Algerians North } \\
\text { African }\end{array}$ & Survey \\
\hline Unger and Meiran, 2020 & United States & Survey \\
\hline Viktoria and Aida, 2020 & Japanese, Russian & Survey \\
\hline Yurdal et al., 2021 & Turkey & Survey \\
\hline
\end{tabular}

In order to perform the aim, the articles were searched through ERIC database. We use "Distance learning" AND "University" AND "COVID" as search terms. We obtained 139 articles. We selected "full text" and "Peer reviewed only" articles. After the exclusion, 58 articles endured. Then content analyses were used to determine articles related to students' voices about distance learning. In the final list, there were 27 articles (Table 1).

In the study, a qualitative approach and content analyses were preferred. Firstly, the findings related to students' attitudes and opinions on distance learning were determined. The research team read selected sections independently. Researchers have come to a consensus on the themes of perception and attitudes, advantages of distance learning, disadvantages of distance learning, and challenges for distance learning. It was decided which study would be included in which theme/s. Finally, the findings were synthesized under themes.

Only 3 studies (Lassoued et al., 2020; Viktoria and Aida, 2020; Todri et al., 2021) were conducted to cover more than one country. Other studies include only one country. Surveys and questionnaires were mostly used as measurement tools in the study. Due to pandemic restrictions, online data collection approaches were preferred in the data collection process.

Students' views on distance learning are grouped under four themes. These themes are perception and attitudes, advantages of distance learning, disadvantages of distance learning, and challenges for distance learning.

\section{Perception and Attitudes Toward Distance Learning}

Students' attitudes toward distance learning differ according to the studies. In some studies (Mathew and Chung, 2020; Avsheniuk et al., 2021), it is stated that especially the students' attitudes are positive, while in some studies (Bozavl1, 2021; Yurdal et al., 2021) it is clearly stated that their attitudes are negative. In addition, there are also studies (Akcil and Bastas, 2021) that indicate that students' attitudes are at a moderate level. The transition to distance learning has been a source of anxiety for some students (Unger and Meiran, 2020).

When the students' satisfaction levels are analyzed, it is obvious from the research (Gonçalves et al., 2020; Avsheniuk et al., 2021; Bakhov et al., 2021; Glebov et al., 2021; Todri et al., 2021) that the students' satisfaction levels are high. In some studies, it is pronounced that the general satisfaction level of the participants is moderate (Viktoria and Aida, 2020; Aldossary, 2021; Didenko et al., 2021) and low (Taşkaya, 2021).

When students compare face-to-face and online learning methods, they state that online learning has opportunities to compensate for their deficiencies due to the pandemic conditions (Abrosimova, 2020) and but they prefer face-to-face learning (Gonçalves et al., 2020; Kaisar and Chowdhury, 2020; Bakhov et al., 2021). Distance learning is not sufficiently motivating (Altun et al., 2021; Bozavlı, 2021), effective (Beltekin and Kuyulu, 2020; Bozavl1, 2021), and does not have a contribution to students' knowledge (Taşkaya, 2021). Distance education cannot be used in place of face-to-face instruction (Aldossary, 2021; Altun et al., 2021).

\section{Advantages of Distance Learning}

It is mostly cited advantages that distance learning has a positive effect on achievement and learning (Gonçalves et al., 2020; Lin and Gao, 2020; Aldossary, 2021; Altun et al., 2021; Şahin, 2021). In addition, in distance learning, students can have more resources and reuse resources such as re-watching video (Önöral and Kurtulmus-Yilmaz, 2020; Lamanauskas and MakarskaitèPetkevičiené, 2021; Martha et al., 2021).

Distance learning for the reason any time and everywhere learning (Adnan and Anwar, 2020; Lamanauskas and Makarskaitè-Petkevičiené, 2021; Todri et al., 2021). There is no need to spend money on transportation to and from the institution (Lamanauskas and MakarskaitéPetkevičienè, 2021; Nenakhova, 2021). Also, staying at home is safe during pandemics and less stressful for students (Lamanauskas and Makarskaitè-Petkevičienè, 2021). 


\section{Challenges and Disadvantages of Distance Learning}

Distance learning cannot guarantee effective learning, the persistence of learning, or success (Altun et al., 2021; Benadla and Hadji, 2021). Students state that they have more works, tasks, and study loads in the distance learning process (Mathew and Chung, 2020; Bakhov et al., 2021; Didenko et al., 2021; Nenakhova, 2021). Group working and socialization difficulties are experienced in distance learning (Adnan and Anwar, 2020; Bozavl1, 2021; Lamanauskas and MakarskaitéPetkevičiene, 2021). The absence of communication and face-to-face interaction is seen a disadvantage (Didenko et al., 2021; Nenakhova, 2021).

It is difficult to keep attention on the computer screen for a long time, so distance-learning negatively affects concentration (Bakhov et al., 2021; Lamanauskas and Makarskaite-Petkevičienè, 2021). In addition, distance education prompts some physical and psychological health problems (Kaisar and Chowdhury, 2020; Taşkaya, 2021).

Devices and internet connection, technical problems are mainly stated as challenges for distance learning (Abrosimova, 2020; Adnan and Anwar, 2020; Mathew and Chung, 2020; Bakhov et al., 2021; Benadla and Hadji, 2021; Didenko et al., 2021; Lamanauskas and Makarskaitè-Petkevičienè, 2021; Nenakhova, 2021; Taşkaya, 2021; Şahin, 2021). In addition, some students have difficulties in finding a quiet and suitable environment where they can follow distance education courses (Taşkaya, 2021). It is a disadvantage that students have not the knowledge and skills to use the technological tools used in distance education (Lassoued et al., 2020; Bakhov et al., 2021; Didenko et al., 2021).

\section{DISCUSSION}

The purpose of this study is to ascertain university students' perceptions about distant education during COVID-19. The study's findings are intended to give context for developers of distant curriculum and higher education institutions.

According to Toquero (2020), academic institutions have an increased need to enhance their curricula, and the incorporation of innovative teaching methods and tactics should be a priority. COVID-19's lockout has shown the reality of higher education's current state: Progressive universities operating in the twentyfirst century did not appear to be prepared to implement digital teaching and learning tools; existing online learning platforms were not universal solutions; teaching staff were not prepared to teach remotely; their understanding of online teaching was sometimes limited to sending handbooks, slides, sample tasks, and assignments to students via email and setting deadlines for submission of completed tasks (Didenko et al., 2021).

It is a key factor that student satisfaction to identify the influencers that emerged in online higher education settings (Parahoo et al., 2016). Also, there was a significant positive relationship between online learning, social presence and satisfaction with online courses (Stankovska et al., 2021). According to the findings, the attitudes and satisfaction levels of the students differ according to the studies and vary in a wide range from positive to negative attitudes.

According to the study's findings, students responded that while online learning is beneficial for compensating for deficiencies during the pandemic, they would prefer face-to-face education in the future. This is a significant outcome for institutions. It is not desirable for all students to take their courses entirely online. According to Samat et al. (2020), the one-size-fits-all approach to ODL implementation is inapplicable since it not only impedes the flow of information delivery inside the virtual classroom, but it also has an impact on psychological well-being because users are prone to become disturbed.

In distance learning, students can have more resources and reuse resources such as re-watching videos. So, distance learning has a positive effect on achievement and learning. Alghamdi (2021) stated that over the last two decades, research on the influence of technology on students' academic success has revealed a range of good and negative impacts and relationships, as well as zero effects and relationship.

The result also shows that distance education prompts some physical and psychological health problems. Due to the difficulty of maintaining focus on a computer screen for an extended period of time, remote education has a detrimental effect on concentration. There is some evidence that students are fearful of online learning in compared to more traditional, or in-person, in-class learning environments, as well as media representations of emergencies (Müller-Seitz and Macpherson, 2014).

Unsatisfactory equipment and internet connection, technical difficulties, and a lack of expertise about remote learning technology are frequently cited as distance learning issues. Due to the pandemic's quick move to online education, many schools have an insufficient infrastructure. Infrastructure deficiency is more evident in fields that require laboratory work such as engineering (Andrzej, 2020) and medicine (Yurdal et al., 2021).

\section{Conclusion and Recommendation}

To sum up, students' opinions and levels of satisfaction vary significantly, ranging from positive to negative. Distance learning for the reason any time and everywhere learning. Distance learning has a positive effect on achievement and learning. Staying at home is safe during pandemics and less stressful for students. Distance education prompts some physical and psychological health problems such as fear, anxiety, stress, and losing concentration. Due to the pandemic's quick move to online education, many schools have an insufficient infrastructure. Future researchers can investigate what distance education models can be that will eliminate the complaints of students. Students' positive attitudes and levels of satisfaction with their distant education programs have an impact on their ability to profit from the program. Consequently, schools wishing to implement distant education should begin by developing a structure, content, and pedagogical approach that would improve the satisfaction of their students. According to the findings of the study, there is no universally applicable magic formula since student satisfaction differs depending on the country, course content, and external factors. 


\section{AUTHOR CONTRIBUTIONS}

All authors listed have made a substantial, direct, and intellectual contribution to the work, and approved it for publication.

\section{REFERENCES}

Abrosimova, G. A. (2020). Digital literacy and digital skills in university study. Int. J. High. Educ. 9, 52-58. doi: 10.5430/ijhe.v9n8p52

Adnan, M., and Anwar, K. (2020). Online learning amid the COVID-19 pandemic: students perspectives. J. Pedagog. Soc. Psychol. 1, 45-51. doi: 10.33902/JPSP. 2020261309

Akhmadieva, R. S., Mikhaylovsky, M. N., Simonova, M. M., Nizamutdinova, S. M., Prokopyev, A. I., and Ostanina, S. S. (2021). Public relations in organizations in sportsman students view: development of management tools or healthy and friendly relations formation. J. Hum. Sport Exerc. 16, 1272-1279. doi: 10.14198/ jhse.2021.16.Proc3.43

Akcil, U., and Bastas, M. (2021). Examination of university students' attitudes towards e-learning during the COVID-19 pandemic process and the relationship of digital citizenship. Contemp. Educ. Technol. 13:e291. doi: 10. 30935/CEDTECH/9341

Aldossary, K. (2021). Online distance learning for translation subjects: tertiary level instructors' and students' perceptions in Saudi Arabia. Turk. Online J. Distance Educ. 22:6.

Alghamdi, A. (2021). COVID-19 mandated self-directed distance learning: experiences of Saudi female postgraduate students. J. Univ. Teach. Learn. Pract. 18:014. doi: 10.53761/1.18.3.14

Altun, T., Akyıldız, S., Gülay, A., and Özdemir, C. (2021). Investigating education faculty students 'views about asynchronous distance education practices during COVID-19. Psycho Educ. Res. Rev. 10, 34-45.

Andrzej, O. (2020). Modified blended learning in engineering higher education during the COVID-19 lockdown - building automation courses case study. Educ. Sci. 10:292.

Avsheniuk, N., Seminikhyna, N., Svyrydiuk, T., and Lutsenko, O. (2021). ESP students' satisfaction with online learning during the COVID-19 pandemic in ukraine. Arab World Engl. J. 1, 222-234. doi: 10.24093/awej/covid.17

Bakhov, I., Opolska, N., Bogus, M., Anishchenko, V., and Biryukova, Y. (2021). Emergency distance education in the conditions of COVID-19 pandemic: experience of Ukrainian universities. Educ. Sci. 11:364. doi: 10.3390/ educsci11070364

Beltekin, E., and Kuyulu, İ (2020). The effect of coronavirus (COVID19) outbreak on education systems: evaluation of distance learning system in Turkey. J. Educ. Learn. 9:1. doi: 10.5539/jel.v9n4p1

Benadla, D., and Hadji, M. (2021). EFL students affective attitudes towards distance e-learning based on moodle platform during the COVID-19 the pandemic: perspectives from Dr. Moulaytahar university of Saida, Algeria. Arab World Engl. J. 1, 55-67. doi: 10.24093/awej/covid.4

Bozavl1, E. (2021). Is foreign language teaching possible without school? Distance learning experiences of foreign language students at Ataturk university during the COVID-19 pandemic. Arab World Engl. J. 12, 3-18. doi: 10.24093/awej/ vol12no1.1

Bozkurt, A., and Sharma, R. (2020). Emergency remote teaching in a time of global crisis due to CoronaVirus pandemic. Asian J. Distance Educ. 15:2020.

Debeş, G. (2021). Distance learning in higher education during the COVID-19 pandemic: advantages and disadvantages. Int. J. Curr. Instr. 13, 1109-1118.

Didenko, I., Filatova, O., and Anisimova, L. (2021). COVID-19 lockdown challenges or new era for higher education. Propós. Represent. 9:e914. doi: 10.20511/pyr2021.v9nspe1.914

Falode, O. C., Chukwuemeka, E. J., Bello, A., and Baderinwa, T. (2020). Relationship between flexibility of learning, support services and students attitude towards distance learning programme in Nigeria. Eur. J. Interact. Multimed. Educ. 1:e02003. doi: 10.30935/ejimed/8320

Gaba, A. K., Bhushan, B., and Kant Rao, D. (2021). Factors influencing the preference of distance learners to study through online during COVID-19 pandemic. Asian J. Distance Educ. 16:2021.

\section{FUNDING}

This manuscript has been supported by the Kazan Federal University Strategic Academic Leadership Program.

Glebov, V. A., Popov, S. I., Lagusev, Y. M., Krivova, A. L., and Sadekova, S. R. (2021). Distance learning in the humanitarian field amid the coronavirus pandemic: risks of creating barriers and innovative benefits. Propós. Represent. 9:e1258. doi: 10.20511/pyr2021.v9nspe3.1258

Gonçalves, S. P., Sousa, M. J., and Pereira, F. S. (2020). Distance learning perceptions from higher education students-the case of Portugal. Educ. Sci. 10:374. doi: 10.3390/educsci10120374

Graham, S. R., Tolar, A., and Hokayem, H. (2020). Teaching preservice teachers about COVID-19 through distance learning. Electron. J. Res. Sci. Math. Educ. 24, 29-37.

Insorio, A. O., and Macandog, D. M. (2022). Video lessons via youtube channel as mathematics interventions in modular distance learning. Contemp. Math. Sci. Educ. 3:e22001. doi: 10.30935/conmaths/11468

Kaisar, M. T., and Chowdhury, S. Y. (2020). Foreign language virtual class room: anxiety creator or healer? Engl. Lang. Teach. 13:130. doi: 10.5539/elt. v13n11p130

Lamanauskas, V., and Makarskaitè-Petkevičienè, R. (2021). Distance lectures in university studies: advantages, disadvantages, improvement. Contemp. Educ. Technol. 13:e309. doi: 10.30935/cedtech/10887

Lassoued, Z., Alhendawi, M., and Bashitialshaaer, R. (2020). An exploratory study of the obstacles for achieving quality in distance learning during the COVID-19 pandemic. Educ. Sci. 10:232. doi: 10.3390/educsci10090232

Lin, X., and Gao, L. (2020). Students' sense of community and perspectives of taking synchronous and asynchronous online courses. Asian J. Distance Educ. 15, 169-179. doi: 10.5281/zenodo.3881614

Martha, A. S. D., Junus, K., Santoso, H. B., and Suhartanto, H. (2021). Assessing undergraduate students' e-learning competencies: a case study of higher education context in Indonesia. Educ. Sci. 11:189. doi: 10.3390/educsci11040189

Mathew, V. N., and Chung, E. (2020). University students' perspectives on open and distance learning (ODL) implementation amidst COVID-19. Asian J. Univ. Educ. 16, 152-160. doi: 10.24191/ajue.v16i4.11964

Müller-Seitz, G., and Macpherson, A. (2014). Learning during crisis as a 'war for meaning': the case of the German Escherichia coli outbreak in 2011. Manag. Learn. 45, 593-608.

Nenakhova, E. (2021). Distance learning practices on the example of second language learning during coronavirus epidemic in Russia. Int. J. Instr. 14, 807-826. doi: 10.29333/iji.2021.14347a

Önöral, Ö, and Kurtulmus-Yilmaz, S. (2020). Influence of COVID-19 pandemic on dental education in cyprus: preclinical and clinical implications with E-learning strategies. Adv. Educ. 7, 69-77.

Palatovska, O., Bondar, M., Syniavska, O., and Muntian, O. (2021). Virtual minilecture in distance learning space. Arab World Engl. J. 1, 199-208. doi: 10.24093/ awej/covid.15

Parahoo, S. K., Santally, M. I., Rajabalee, Y., and Harvey, H. L. (2016). Designing a predictive model of student satisfaction in online learning. J. Market. High. Educ. 26, 1-19. doi: 10.1080/08841241.2015.1083511

Samat, M. F., Awang, N. A., Hussin, S. N. A., and Nawi, F. A. M. (2020). Online distance learning amidst COVID-19 pandemic among university students: a practicality of partial least squares structural equation modelling approach. Asian J. Univ. Educ. 16, 220-233.

Simonson, M., and Berg, G. A. (2016). Distance Learning. In Encyclopedia Britannica. Available online at: https://www.britannica.com/topic/distancelearning (accessed November 14, 2011).

Stankovska, G., Dimitrovski, D., and Ibraimi, Z. (2021). "Online learning, social presence and satisfaction among university students during the COVID-19 pandemic," in Paper Presented at the Annual International Conference of the Bulgarian Comparative Education Society (BCES), (Sofia), 181-188.

Şahin, M. (2021). Opinions of university students on effects of distance learning in Turkey during the COVID-19 pandemic. Afr. Educ. Res. J. 9, 526-543. doi: 10.30918/aerj.92.21.082 
Tal, C., Tish, S., and Tal, P. (2022). Parental perceptions of their preschool and elementary school children with respect to teacher-family relations and teaching methods during the first COVID-19 lockdown. Pedagog. Res. 7:em0114. doi: $10.29333 / \mathrm{pr} / 11518$

Taşkaya, S. M. (2021). Teacher candidates' evaluation of the emergency remote teaching practices in turkey during COVID-19 pandemic. Int. J. Progress. Educ. 17, 63-78. doi: 10.29329/ijpe.2021.366.5

Todri, A., Papajorgji, P., Moskowitz, H., and Scalera, F. (2021). Perceptions regarding distance learning in higher education, smoothing the transition. Contemp. Educ. Technol. 13:e287. doi: 10.30935/cedtech/9274

Toquero, C. M. (2020). Challenges and opportunities for higher education amid the COVID-19 pandemic: the Philippine context. Pedagog. Res. 5:em0063. doi: $10.29333 / \mathrm{pr} / 7947$

Tugun, V., Bayanova, A. R., Erdyneeva, K. G., Mashkin, N. A., Sakhipova, Z. M., and Zasova, L. V. (2020). The opinions of technology supported education of university students. Int. J. Emerg. Technol. Learn. 15, 4-14. doi: 10.3991/ijet. v15i23.18779

Unger, S., and Meiran, W. (2020). Student attitudes towards online education during the COVID-19 viral outbreak of 2020: distance learning in a time of social distance. Int. J. Technol. Educ. Sci. 4, 256-266. doi: 10.46328/ijtes.v4i4.107

Valeeva, R., and Kalimullin, A. (2021). Adapting or changing: the COVID-19 pandemic and teacher education in Russia. Educ. Sci. 11:408. doi: 10.3390/ educsci11080408

Viktoria, V., and Aida, M. (2020). comparative analysis on the impact of distance learning between Russian and Japanese university students, during the pandemic of COVID-19. Educ. Q. Rev. 3:438-446. doi: 10.31014/aior.1993.03. 04.151

Virtič, M. P., Dolenc, K., and Šorgo, A. (2021). Changes in online distance learning behaviour of university students during the coronavirus disease 2019 outbreak, and development of the model of forced distance online learning preferences. Eur. J. Educ. Res. 10, 393-411. doi: 10.12973/EU-JER.10.1.393

Yurdal, M. O., Sahin, E. M., Kosan, A. M. A., and Toraman, C. (2021). Development of medical school students' attitudes towards online learning scale and its relationship with E-learning styles. Turk. Online J. Distance Educ. 22, 310-325. doi: 10.17718/tojde.961855

Zagkos, C., Kyridis, A., Kamarianos, I., Dragouni, KE., Katsanou, A., Kouroumichaki, E., et al. (2022). Emergency remote teaching and learning in greek universities during the COVID-19 pandemic: the attitudes of university students. Eur. J. Interact. Multimed. Educ. 3:e02207. doi: 10.30935/ejimed/11494

Conflict of Interest: The authors declare that the research was conducted in the absence of any commercial or financial relationships that could be construed as a potential conflict of interest.

Publisher's Note: All claims expressed in this article are solely those of the authors and do not necessarily represent those of their affiliated organizations, or those of the publisher, the editors and the reviewers. Any product that may be evaluated in this article, or claim that may be made by its manufacturer, is not guaranteed or endorsed by the publisher.

Copyright (๑ 2022 Masalimova, Khvatova, Chikileva, Zvyagintseva, Stepanova and Melnik. This is an open-access article distributed under the terms of the Creative Commons Attribution License (CC BY). The use, distribution or reproduction in other forums is permitted, provided the original author(s) and the copyright owner(s) are credited and that the original publication in this journal is cited, in accordance with accepted academic practice. No use, distribution or reproduction is permitted which does not comply with these terms. 